\title{
ESTUDO DE SORÇÃO DE HERBICIDAS PELOS ARGILOMINERAIS VERMICULITA E MONTMORILONITA
}

Edivaltrys Inayve Pissinati de Rezende, Patricio Guillermo Peralta-Zamora e Gilberto Abate*

Departamento de Química, Universidade Federal do Paraná, CP 19081, 81531-990 Curitiba - PR, Brasil

Recebido em 13/11/09; aceito em 5/7/10; publicado na web em 9/11/10

\begin{abstract}
SORPTION STUDY OF HERBICIDES WITH THE CLAY MINERALS VERMICULITE AND MONTMORILLONITE. The clay minerals montmorillonite (MT) and vermiculite (VT), previously treated with $\mathrm{Ca}^{2+}, \mathrm{K}^{+}$and $\mathrm{Na}^{+}$, were employed in a sorption study with herbicides. The herbicides 2,4-D, diuron, alachlor and metolachlor showed no interaction with MT and VT. On the other hand, the triazines presented a good sorption process, close to $100 \%$ for ametrine removal and near to 56 and $69 \%$ for atrazine and simazine, respectively, by MT. These results suggest that the MT specie may be a good material for triazines removal from aqueous medium and an alternative phase to preconcentration process, besides to exhibit a good selectivity.
\end{abstract}

Keywords: clay minerals; preconcentration; water.

\section{INTRODUÇÃO}

Dos pesticidas utilizados na agricultura, aproximadamente $50 \%$ do total se referem ao uso de herbicidas, sendo esta a classe dos agrotóxicos de maior utilização em nível mundial. ${ }^{1,2}$ Muitos desses herbicidas apresentam elevada toxicidade ao ser humano, bem como baixa taxa de mineralização, com consequente persistência nos solos, podendo atingir rios, lagos e águas subterrâneas, devido à permeação através dos solos. Isso tem gerado uma série de problemas ambientais ao longo dos anos, no Brasil e em outros países. ${ }^{3-5}$

No Brasil o consumo de herbicidas é bastante elevado em especial nas regiões sul, sudeste e centro-oeste com destaque para as culturas de soja, milho, cana-de-açúcar e arroz. Essas regiões por sua vez, classificadas como as mais desenvolvidas no que diz respeito à produção agrícola em território nacional, além de parte da Argentina, Paraguai e Uruguai, são abrangidas pelo maior reservatório de água doce do mundo, o Aquífero Guarani. Sendo assim, as possibilidades de contaminação de águas subterrâneas são amplas, dependendo das características do solo e dos herbicidas utilizados. ${ }^{6}$ Dessa forma, a legislação brasileira CONAMA n 357 de 2005 regulamenta os níveis máximos de pesticidas em corpos de água, baseados em sua periculosidade, assim como estabelece as condições e padrões de efluentes para o lançamento em corpos hídricos. ${ }^{7}$ Os herbicidas ametrina, atrazina, simazina, alacloro, metolacloro e diuron são classificados pelo Ministério da Saúde como medianamente tóxicos (classificação III), ao passo que o 2,4-D, é classificado como extremamente tóxico (classificação I) aos organismos vivos, ${ }^{8}$ e estão entre os herbicidas mais comercializados no Brasil. ${ }^{9}$ Somente para os dois primeiros agroquímicos não há legislação vigente; para os demais, a concentração máxima na água potável é de $2 \mu \mathrm{g} \mathrm{L}{ }^{-1}$ para a atrazina e simazina, $10 \mu \mathrm{g} \mathrm{L}^{-1}$ para o metolacloro, $20 \mu \mathrm{g} \mathrm{L}^{-1}$ para o alacloro e $4 \mu \mathrm{g} \mathrm{L}^{-1}$ para o $2,4-\mathrm{D} .^{7}$

Face ao exposto, um grande número de estudos envolvendo a interação entre herbicidas e solos, ${ }^{10-13}$ ou com componentes dos solos, ${ }^{14,15}$ vem sendo conduzido, visando principalmente conhecer o possível comprometimento do solo e de águas subterrâneas. Dentre tais estudos, um enfoque especial pode ser dado aos argilominerais em suas formas naturais ou modificadas, para possíveis aplicações direcionadas para tratamento de águas, ${ }^{16-18}$ recuperação ou preserva-

*e-mail: gilbertoabate@ufpr.br ção de solos, ${ }^{19,20}$ ou ainda no desenvolvimento de formulações com liberação controlada de herbicidas no solo. ${ }^{20-23}$ Isso se deve a algumas propriedades desses minerais como, por exemplo, elevada área superficial e grande capacidade de troca catiônica (CTC), podendo apresentar valores entre 80 e $200 \mathrm{mmol} / 100 \mathrm{~g}$ de argilomineral, ${ }^{22}$ que aliadas ao baixo custo, grande disponibilidade, boa inércia química e facilidade para purificação propicia que essas fases minerais sejam bastante favoráveis para atuarem como concentradores analíticos. Nesse sentido, um considerável volume de pesquisa envolvendo argilominerais purificados nas formas naturais ou modificadas vem sendo realizado; contudo, com aplicações voltadas para espécies inorgânicas. ${ }^{24-27}$ Assim, procedimentos envolvendo argilominerais direcionados para concentração de espécies orgânicas podem constituir uma atrativa alternativa frente às fases sorventes investigadas em processos por extração em fase sólida (SPE) $;{ }^{28-30}$ o que, entretanto, vem sendo pouco explorado..$^{31,32}$

O presente trabalho teve como propósito estudar o potencial dos argilominerais montmorilonita e vermiculita previamente tratados, no processo de sorção dos herbicidas 2,4-D (ácido ariloxialcanoico), ${ }^{8}$ diuron (uréia), ${ }^{8}$ alacloro e metolacloro (cloroacetanilidas), ${ }^{8}$ atrazina, ametrina e simazina (triazinas), ${ }^{8}$ os quais possuem grande utilização no Brasil. Tal estudo permitiu avaliar essas fases minerais como materiais alternativos na remoção desses compostos de meio aquoso, bem como verificar a possibilidade de emprego dos mesmos como concentradores analíticos. Foi adotado processo em batelada para realização dos estudos de sorção, sendo as concentrações dos herbicidas determinadas por injeção em fluxo na região do ultravioleta (FIA-UV).

\section{PARTE EXPERIMENTAL}

\section{Equipamentos, reagentes e materiais}

Para determinação do comprimento de onda $(\lambda)$ de máxima absorção, foi utilizado um espectrofotômetro da marca Shimadzu, UV 2401 PC, efetuando-se as leituras entre 190 e $820 \mathrm{~nm}$, para cada um dos herbicidas estudados, empregando cela de quartzo com $1,0 \mathrm{~cm}$ de caminho óptico. As curvas analíticas para cada um dos herbicidas, bem como para a quantificação dos extratos aquosos, foram obtidas por espectrofotometria na região do ultravioleta (UV). Para tal, foi empregado um espectrofotômetro da marca Femto, 700 Plus, previa- 
mente ajustado no comprimento de onda compatível com cada um dos herbicidas. Uma cela de fluxo em quartzo com caminho óptico de 1,0 cm, marca Hellma, foi acoplada, utilizando uma bomba peristáltica da marca Ismatec, 78016-30, como sistema de propulsão e uma válvula de injeção em acrílico de 8 canais (produzida no CENA-USP, Piracicaba), com alça de amostragem de $400 \mu \mathrm{L}$. A condução das soluções foi realizada por tubos de polietileno (diâmetro interno de $0,8 \mathrm{~mm}$ ) e de Tygon para uso na bomba peristáltica (diâmetro interno de $0,8 \mathrm{~mm}$ ). Em todos os experimentos foi utilizada água ultrapura, obtida pelo equipamento da marca Millipore, Simplicity, dotado de lâmpada UV. Para as medidas dos valores de $\mathrm{pH}$, utilizou-se um potenciômetro da marca Hanna, pH 21 e eletrodo de vidro combinado com eletrodo de referência $\mathrm{Ag} / \mathrm{AgCl}$.

Os padrões de herbicidas foram adquiridos da marca Riedel-de Haën, sendo que a Tabela 1 apresenta as principais características físico-químicas dos compostos, juntamente com outras informações relevantes. As soluções estoques individuais dos herbicidas foram preparadas dissolvendo a quantidade apropriada dos padrões em metanol grau cromatográfico, de modo a obter concentrações de 500 ou $1000 \mathrm{mg} \mathrm{L}^{-1}$, sendo essas soluções mantidas em refrigerador a $-18{ }^{\circ} \mathrm{C}$. As soluções intermediárias e de trabalho foram obtidas a partir de diluições sucessivas da solução estoque, com água ultrapura, respeitando-se a solubilidade de cada herbicida em meio aquoso.
Estas soluções foram utilizadas na obtenção das curvas analíticas, bem como em todos os experimentos de sorção. Todos os demais reagentes utilizados foram de grau analítico das marcas Merck, Aldrich, Carlo Erba, JT Baker, ou similar. Para efetuar a filtração das amostras, foram utilizadas membranas descartáveis de acetato de celulose, marca Millipore, com abertura de poro de $0,45 \mu \mathrm{m}$ e $25 \mathrm{~mm}$ de diâmetro, acopladas a seringas hipodérmicas de $10 \mathrm{~mL}$.

\section{Tratamento e caracterização dos argilominerais}

Foram utilizados os argilominerais montmorilonita (MT) K-10, 28152-2 da marca Aldrich e vermiculita (VT) proveniente de uma mina da cidade de Paulistana (PI), fornecida pela empresa Eucatex Química e Mineral Ltda. A VT foi fornecida em grãos de aproximadamente $1,0 \mathrm{~mm}$, sendo triturada com um almofariz e pistilo.

Amostras de 5,0 g de MT e VT foram mantidas sob agitação por 30 min com $50 \mathrm{~mL}$ de solução de $\mathrm{HCl}$ em concentração de $0,05 \mathrm{~mol}$ $\mathrm{L}^{-1}$ sendo, em seguida, centrifugadas (2800 rpm), o sobrenadante descartado e tratadas separadamente com $50 \mathrm{~mL}$ de soluções de $\mathrm{NaCl}, \mathrm{KCl}$ e $\mathrm{CaCl}_{2}$ em concentração de $1,0 \mathrm{~mol} \mathrm{~L}^{-1}$, durante $30 \mathrm{~min}$, sob agitação. As amostras foram novamente centrifugadas e as fases sobrenadantes descartadas. Essa última etapa foi repetida três vezes, a fim de favorecer a obtenção dos argilominerais com predominância

Tabela 1. Principais características físico-químicas dos herbicidas estudados e outras informações relevantes

\begin{tabular}{|c|c|c|c|c|c|c|}
\hline Herbicida & Estrutura $^{8}$ & $\begin{array}{l}\text { Massa molar } \\
\left(\mathrm{g} \mathrm{mol}^{-1}\right)^{33}\end{array}$ & $\begin{array}{c}\text { Solubilidade em água }{ }^{33} \\
\left(\mathrm{mg} \mathrm{L}^{-1}-25^{\circ} \mathrm{C}\right)\end{array}$ & $\log \mathrm{K}_{\mathrm{OW}}$ & $\begin{array}{l}\mathrm{t}_{1 / 2} \text { vida } \\
{\text { (dias) })^{33}}^{\text {ding }}\end{array}$ & $\begin{array}{l}\text { Pureza } \\
(\%)^{a}\end{array}$ \\
\hline $2,4-\mathrm{D}$ & & 221,0 & 600 & $2,6-2,8^{34}$ & 10 & 99,6 \\
\hline Diuron & & 233,0 & 42 & $2,77^{33}$ & 90 & 98,0 \\
\hline Alacloro & 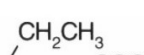 & 269,5 & 200 & $2,90^{33}$ & 42 a 70 & 99,2 \\
\hline Metolacloro & & 283,5 & 480 & $0,48^{33}$ & - & 98,0 \\
\hline Ametrina & & 227,0 & 200 & $2,63^{33}$ & 60 & 98,5 \\
\hline Atrazina & & 215,5 & 33 & $2,68^{33}$ & 60 & 99,0 \\
\hline Simazina & & 201,5 & 3,5 & $2,08^{33}$ & 90 & 99,0 \\
\hline
\end{tabular}

${ }^{a}$ Conforme informações do fabricante 
dos respectivos cátions interlamelares. As fases sólidas foram agitadas com $50 \mathrm{~mL}$ de água ultrapura quatro vezes, para retirada do excesso de sais, sendo mais uma vez utilizado o processo de centrifugação para descarte e troca das águas de lavagens. A seguir, os argilominerais foram secos a $80{ }^{\circ} \mathrm{C}$, triturados em almofariz com pistilo até passarem completamente em uma peneira de malha 100 mesh, peneirados em uma peneira de 195 mesh e estocados em dessecador para uso posterior.

Os argilominerais foram identificados da seguinte forma: MT de cálcio $\left(\mathrm{MT}_{\mathrm{Ca}}\right)$, MT de potássio $\left(\mathrm{MT}_{\mathrm{K}}\right)$, MT de sódio $\left(\mathrm{MT}_{\mathrm{Na}}\right)$, VT de cálcio $\left(\mathrm{VT}_{\mathrm{Ca}}\right)$, VT de potássio $\left(\mathrm{VT}_{\mathrm{K}}\right)$ e VT de sódio $\left(\mathrm{VT}_{\mathrm{Na}}\right)$. Esses materiais foram caracterizados por difração de raios $\mathrm{X}$ (DRX), utilizandose um equipamento da marca Shimadzu, XRD-6000, radiação $\mathrm{Cu}-\mathrm{k} \alpha$ ( $\lambda=1,5418 \AA$ ̊), além de terem sido determinados os valores de área superficial, empregando o equipamento Micromeritics, ASAP 2010.

\section{Avaliação das soluções das provas em branco}

Volumes de 50,0 $\mathrm{mL}$ das suspensões dos sólidos em água ultrapura contendo $\mathrm{MT}_{\mathrm{Ca}}, \mathrm{MT}_{\mathrm{K}}, \mathrm{MT}_{\mathrm{Na}}, \mathrm{VT}_{\mathrm{Ca}}, \mathrm{VT}_{\mathrm{K}}$ e $\mathrm{VT}_{\mathrm{Na}}$ foram preparados em tubos de polipropileno, de modo a proporcionar concentrações de 1,0 e $2,0 \mathrm{~g} \mathrm{~L}^{-1}$. Os tubos foram agitados em uma mesa orbital por $1 \mathrm{~h}$, centrifugados a $2800 \mathrm{rpm}$ por $5 \mathrm{~min}$, sendo as fases sobrenadantes de cada um dos argilominerais retiradas e divididas em quatro alíquotas (A, B, C e D), as quais foram tratadas da seguinte forma: A - não foi submetida a nenhum tratamento; $\mathrm{B}$ - foi filtrada em membrana de $0,45 \mu \mathrm{m} ; \mathrm{C}$ - recebeu a adição de $\mathrm{NaCl}$ de modo a proporcionar a concentração de $1,0 \mathrm{~mol} \mathrm{~L}^{-1}$, tendo sido agitada por $1 \mathrm{~min}$, centrifugada e a fase sobrenadante reservada; $\mathrm{D}$ - similar a C, contudo, o segundo sobrenadante foi filtrado em membrana de $0,45 \mu \mathrm{m}$ após a centrifugação. As quatro alíquotas obtidas foram avaliadas na região do UV-VIS (190-820 nm).

\section{Curvas analíticas}

Para a elaboração das curvas analíticas, e posterior quantificação dos extratos dos herbicidas, foi montado um sistema utilizando análise por injeção em fluxo na região do ultravioleta (FIA-UV) empregando os equipamentos descritos anteriormente. Cinco padrões de cada um dos herbicidas foram preparados nas concentrações de 0,$25 ; 0,50$; 1,00; 2,50 e 5,00 $\mathrm{mg} \mathrm{L}^{-1}$; sendo as leituras de absorbância realizadas no sistema FIA-UV, nos comprimentos de onda previamente determinados.

\section{Estudo de sorção}

Esta etapa foi cumprida com os seis argilominerais, para os herbicidas 2,4-D, diuron, alacloro, metolacloro, atrazina, ametrina e simazina. Suspensões foram preparadas em tubos de centrífuga de polipropileno de $15 \mathrm{~mL}$, contendo $1,0 \mathrm{~g} \mathrm{~L}^{-1}$ de cada um dos argilominerais na presença de $2,5 \mathrm{mg} \mathrm{L}^{-1}$ de cada herbicida, sendo preparadas provas em branco em paralelo para cada um dos argilominerais. Todas as suspensões foram agitadas por $30 \mathrm{~min}$, seguindo com a determinação do $\mathrm{pH}$ e centrifugação em $2800 \mathrm{rpm}$ por $5 \mathrm{~min}$. As fases sobrenadantes obtidas foram filtradas em membrana de $0,45 \mu \mathrm{m}$ e, em seguida, foram determinadas as concentrações remanescentes para cada estudo individual dos herbicidas, empregando o sistema FIA-UV, nos comprimentos de onda previamente estabelecidos.

\section{Influência do pH}

Essa etapa foi realizada para o diuron, sendo que as condições de concentrações dos argilominerais e do herbicida, preparo das provas em branco, centrifugação e filtração foram idênticas ao item anterior, contudo, o tempo de contato sob agitação foi de $3 \mathrm{~h}$. Antes do processo de agitação, foi adicionado $\mathrm{HCl}$ às suspensões, para ajuste dos valores de $\mathrm{pH}$, nas concentrações de 2,5; 10 e $100 \mathrm{mmol} \mathrm{L}^{-1}$. Ao final, as amostras e provas em branco foram centrifugadas e filtradas em membrana de $0,45 \mu \mathrm{m}$ e os sobrenadantes analisados empregando o sistema FIA-UV, como anteriormente.

\section{Estudo de dessorção e de recuperação}

Um volume de 50,0 mL de solução de ametrina foi utilizado em concentração de $0,10 \mathrm{mg} \mathrm{L}^{-1}$, sendo essa solução mantida em contato com 50,0 mg de $\mathrm{MT}_{\mathrm{K}}$ em um tubo de centrífuga, sob agitação por $30 \mathrm{~min}$, o qual em seguida foi centrifugado a $2800 \mathrm{rpm}$ por $5 \mathrm{~min}$. A fase sobrenadante foi cuidadosamente retirada e ao sólido restante foi adicionado $0,50 \mathrm{~mL}$ de acetona. A suspensão foi agitada por 1 min manualmente e centrifugada a $2800 \mathrm{rpm}$. Este procedimento foi repetido três vezes. As fases sobrenadantes foram volatilizadas e transferidas quantitativamente com água ultrapura para balão volumétrico de $5 \mathrm{~mL}$. As amostras foram filtradas em membrana de 0,45 $\mu \mathrm{m}$, sendo as concentrações de ametrina determinadas por FIA-UV.

\section{RESULTADOS E DISCUSSÃO}

\section{Tratamento e caracterização dos argilominerais}

Para a remoção de possíveis impurezas que poderiam estar sorvidas na superfície ou, até mesmo, entre as lamelas dos argilominerais e assim interferir no processo de concentração ou eventualmente gerar espécies que poderiam absorver radiação UV juntamente com as espécies de interesse, foi realizado o tratamento prévio da amostra com $\mathrm{HCl}$. O tratamento com bases fortes não seria adequado, pois haveria a tendência de ocorrer reação com o silicato da estrutura, solubilizando parcialmente o argilomineral, além da possibilidade de favorecer a formação de $\mathrm{Fe}(\mathrm{OH})_{3}$, destruindo desta forma o arranjo estrutural dos minerais. Após a purificação em meio ácido, realizou-se a saturação dos argilominerais com os cátions $\mathrm{Ca}^{2+}, \mathrm{K}^{+} \mathrm{e} \mathrm{Na}^{+}$, visando investigar se haveria influência de diferentes cátions interlamelares no processo de sorção dos herbicidas, visando obter uma melhor homogeneidade para os diferentes experimentos realizados. Esses materiais apresentam capacidade de troca cationnica (CTC) de $0,59 \mathrm{e}$ $1,17 \mathrm{mmol} \mathrm{g}^{-1}$, representados pela $\mathrm{MT}_{\mathrm{K}} \mathrm{eVT}_{\mathrm{K}}$, respectivamente, tendo sido esses valores previamente determinados, ${ }^{16}$ sendo coerentes com resultados usualmente relatados na literatura. ${ }^{22,35}$

A Tabela 2 mostra o percentual dos sólidos que passou na peneira de 100 mesh e ficou retido na peneira de 195 mesh, bem como a determinação do espaçamento basal d(001) e a área superficial (BET). Como pode ser verificado, os percentuais retidos na peneira 195 mesh são de no mínimo 69,2\% ( $\mathrm{VT}_{\mathrm{Na}}$ ) até no máximo de 91,7\% $\left(\mathrm{VT}_{\mathrm{K}}\right)$, ou seja, os materiais utilizados apresentaram, na maior parte, distribuição de grãos de 76,9 (195 mesh) até $150 \mu \mathrm{m}$ (100 mesh), e a menor parte dos minerais possuía diâmetro médio inferior a 76,9 $\mu \mathrm{m}$. Apesar da boa semelhança de distribuição granulométrica, a área superficial $\left(\mathrm{m}^{2}\right.$ $\mathrm{g}^{-1}$ ) de ambos minerais VT e MT foi muito diferente, de 7,4 a 16,7 para VT e de 220 a 242 para MT, o que sugere uma quantidade de sítios disponíveis para sorção muito superior para MT, em decorrência da grande superioridade nos valores de área superficial, frente à VT. Tal diferença já havia sido constatada na literatura na qual foram reportados valores de 31,4 e 228 para $\mathrm{VT}_{\mathrm{K}}$ e $\mathrm{MT}_{\mathrm{K}}$, respectivamente. ${ }^{16}$

Dependendo das condições do meio como $\mathrm{pH}$ e força iônica, as interações entre as fases sorventes com os herbicidas podem ocorrer por troca iônica e outras formas de interação, como ligações de van der Waals e ligações de hidrogênio, ${ }^{20,21}$ e dessa forma os valores 
de área superficial elevados podem ter um papel fundamental em processos de sorção. Os valores de espaçamento basal $(\AA)$ obtidos para $\mathrm{MT}_{\mathrm{Ca}}, \mathrm{MT}_{\mathrm{K}}$ e $\mathrm{MT}_{\mathrm{Na}}$ foram iguais entre si $(9,9 \AA)$ e discrepantes de valores usualmente relatados na literatura, ${ }^{19,35}$ os quais variam de aproximadamente 10 para montmorilonitas saturadas com potássio até por volta de 14 para aquelas saturadas com cálcio, em decorrência do maior grau de hidratação desse último cátion. ${ }^{35}$ Outro aspecto a ser ressaltado é que a MT K-10, na forma original, apresentou espaçamento basal de 10,0 , ou seja, foi constatado não haver modificação nos valores com relação à amostra original, provavelmente em decorrência do tratamento ácido que é empregado nesse material comercial, o que sugere não ter ocorrido a troca com os cátions em questão. De acordo com a literatura, ${ }^{36}$ a MT K-10 é uma argila que praticamente não apresenta sinais correspondentes à fase cristalina de montmorilonita, a qual provavelmente teria sido destruída durante o tratamento industrial. Conforme Rajesh et al. ${ }^{26}$ tratamentos com ácidos fortes em elevadas concentrações podem ocasionar o colapso total do argilomineral e poderiam, inclusive, aumentar o processo de sorção em decorrência da maior exposição de grupos hidroxila superficiais. A VT apresentou valores de 10,$2 ; 12,3 ; 14,1$ e $14,2 \AA$ para $\mathrm{VT}_{\mathrm{K}}, \mathrm{VT}_{\mathrm{Na}}, \mathrm{VT}_{\mathrm{Ca}}$ e VT natural antes da realização do tratamento ácido e da saturação, respectivamente, sendo tais valores coerentes com aqueles descritos na literatura ${ }^{35,37}$ para esse argilomineral. Isso é indicativo que o tratamento ácido realizado neste estudo não ocasionou modificações significativas nos valores de espaçamento basal para a VT, em comparação com os dados da literatura; o que reforça a hipótese de que a causa de não ter ocorrido modificação nos valores de espaçamento basal para MT tenha sido o tratamento ácido originalmente realizado para esse argilomineral.

Tabela 2. Percentual de retenção na peneira de 195 mesh, espaçamento basal d(001) e área superficial (BET)

\begin{tabular}{lccc}
\hline Argilomineral & \% retida $(195 \mathrm{mesh})$ & $\mathrm{d}(001)-\AA$ & Área $\left(\mathrm{m}^{2} \mathrm{~g}^{-1}\right)$ \\
\hline $\mathrm{MT}_{\mathrm{Ca}}$ & 85,7 & 9,9 & 223 \\
$\mathrm{MT}_{\mathrm{K}}$ & 80,2 & 9,9 & 242 \\
$\mathrm{MT}_{\mathrm{Na}}$ & 75,0 & 9,9 & 220 \\
$\mathrm{VT}_{\mathrm{Ca}}$ & 88,0 & 14,4 & 7,4 \\
$\mathrm{VT}_{\mathrm{K}}$ & 91,7 & 10,2 & 16,7 \\
$\mathrm{VT}_{\mathrm{Na}}$ & 69,2 & 12,3 & 15,7 \\
\hline
\end{tabular}

\section{Avaliação das soluções das provas em branco}

Foi realizado um teste preliminar para verificar se as provas em branco dos argilominerais poderiam liberar espécies que absorvessem radiação na região do UV, pois mesmo espécies minerais, como os sorventes utilizados neste estudo, absorvem radiação nessa região do espectro. Essa etapa foi realizada para as três vermiculitas saturadas com sódio, potássio e cálcio e de forma idêntica para as três montmorilonitas, totalizando seis amostras. Para cada um dos seis materiais, foram obtidas quatro fases sobrenadantes, as quais foram analisadas por espectrofotometria, sendo os quatro espectros obtidos para os argilominerais saturados com o íon $\mathrm{Na}^{+}$mostrados na Figura 1 e identificados como MT1, MT2, VT1 e VT2, sendo que os números 1 e 2 identificam as concentrações utilizadas de argilomineral de 1,0 ou 2,0 $\mathrm{g} \mathrm{L}^{-1}$, respectivamente. Essas diferentes concentrações foram adotadas, visando verificar se haveria influência do aumento da concentração de sólidos na solução após centrifugação, o que foi comprovado pelos maiores sinais observados para as concentrações de sólidos de 2,0 $\mathrm{g} \mathrm{L}^{-1}$, conforme Figura 1. Deve-se salientar que a Figura 1 evidencia somente as amostras de $\mathrm{VT}_{\mathrm{Na}}$ e $\mathrm{MT}_{\mathrm{Na}}$, sendo que para os demais argilominerais saturados com cálcio ou potássio os resultados foram muito semelhantes e, por isso, foram omitidos. Para todos os argilominerais, as provas em branco apresentaram sinais muito elevados de absorbância, quando apenas o processo de centrifugação era realizado, de acordo com a Figura 1, apesar das soluções obtidas após centrifugação serem visualmente límpidas, para ambas as concentrações dos sólidos $\left(1,0\right.$ ou 2,0 $\left.\mathrm{g} \mathrm{L}^{-1}\right)$.

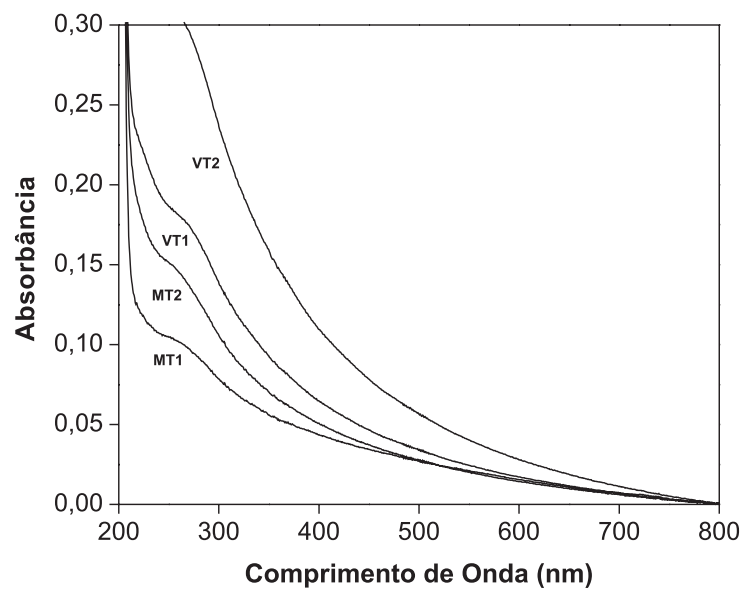

Figura 1. Espectros de absorção obtidos para as fases sobrenadantes após centrifugação, para os argilominerais saturados com o ion sódio (MT1) $M T_{N a}$ $1,0 \mathrm{~g} \mathrm{~L}^{-1}$; (MT2) $M T_{\mathrm{Na}} 2,0 \mathrm{~g} \mathrm{~L}^{-1}$; (VT1) $V T_{\mathrm{Na}} 1,0 \mathrm{~g} \mathrm{L^{-1 }}$; (VT2) $V T_{\mathrm{Na}} 2,0 \mathrm{~g} \mathrm{~L}^{-1}$

Dessa forma, procedimentos adicionais foram realizados, implementando-se a filtração em membrana com abertura de poro de $0,45 \mu \mathrm{m}$, bem como a tentativa de utilizar a adição de $\mathrm{NaCl}$, conforme descrito na parte experimental, em avaliação das soluções das provas em branco. A Figura 2 mostra os espectros obtidos para as fases sobrenadantes para os mesmos argilominerais, após centrifugação, adição de $\mathrm{NaCl}$ nas fases sobrenadantes, nova centrifugação e filtração em membrana. Em decorrência da grande similaridade entre os espectros, os mesmos não foram identificados na Figura 2, o que evidencia uma ótima confiabilidade nos sinais das provas em branco, ficando para os quatro casos os sinais muito próximos à linha base. Deve-se ressaltar que apenas a realização da filtração em membrana após a centrifugação mostrou espectros muitos similares àqueles da Figura 2 (procedimento $\mathrm{B}$ ) o que evidencia não haver necessidade da adição de $\mathrm{NaCl}$ (procedimento D). Isso levou-nos a adotar o procedimento B para a realização das determinações das concentrações dos herbicidas. Cabe salientar que para $\mathrm{MT}_{\mathrm{K}}, \mathrm{MT}_{\mathrm{Ca}}$, $\mathrm{VT}_{\mathrm{K}}$ e $\mathrm{VT}_{\mathrm{Ca}}$ os resultados foram muito similares e, assim, foram omitidos. Esses experimentos permitiram constatar a necessidade de um tratamento adequado das fases sobrenadantes, para se poder quantificar as concentrações remanescentes dos herbicidas e realizar o estudo proposto. É provável que tal absorção seja devida à presença de partículas coloidais na solução, para as quais a centrifugação não permite a remoção. Provavelmente, a adição do $\mathrm{NaCl}$ tenha diminuído a estabilidade da suspensão coloidal, propiciando o consequente agrupamento das partículas coloidais com maiores massas, facilitando a sedimentação durante o processo de centrifugação.

\section{Estudo de sorção}

Após uma simples otimização do sistema por injeção em fluxo (FIA-UV), foram determinados como parâmetros ideais uma vazão de $2,7 \mathrm{~mL} \mathrm{~min}^{-1}$, volume de amostra de $400 \mu \mathrm{L}$ e água ultrapura como solução transportadora. Deve-se enfatizar que o estudo poderia ter sido realizado por espectrofotometria sem acoplamento ao sistema 


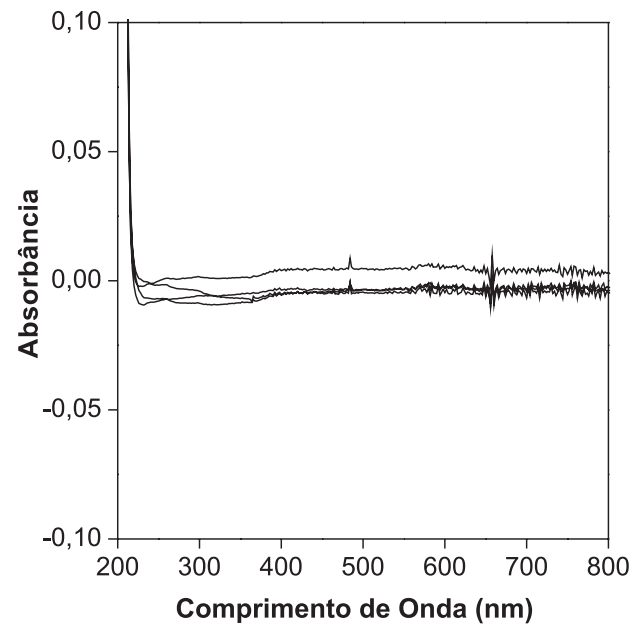

Figura 2. Espectros de absorção obtidos para as fases sobrenadantes após centrifugação, adição de $\mathrm{NaCl}$, centrifugação e filtração em membrana de 0,45 $\mu \mathrm{m}$. Os argilominerais estudados foram os mesmos descritos para a Figura 1

empregando FIA. Todavia, o emprego do sistema FIA visou proporcionar uma maior frequência analítica, especialmente para casos onde o número de amostras foi maior, sendo que pelo fato de não haver desenvolvimento de cor, o processo empregado foi bastante simples e por isso foi utilizado no lugar do modo convencional.

Inicialmente foram obtidos os registros dos sinais para construção das curvas analíticas entre 0,25 e $5,00 \mathrm{mg} \mathrm{L}^{-1}$ para cada um dos herbicidas individualmente. A maioria das curvas analíticas obtidas apresentou $\mathrm{r}^{2}$ superior a 0,999 e boa proporcionalidade para as diferentes concentrações das soluções padrão, com limites de quantificação (LQ) ao redor de $0,20 \mathrm{mg} \mathrm{L}^{-1}$, com base nos sinais das provas em branco.

A Figura 3a mostra como exemplo, os registros obtidos com três injeções para cada padrão de ametrina, bem como os sinais das amostras para o estudo realizado com $\mathrm{MT}_{\mathrm{K}}$, enquanto a Figura $3 \mathrm{~b}$ ilustra o estudo similar para $\mathrm{VT}_{\mathrm{K}}$. De acordo com as Figuras $3 \mathrm{a}$ e $3 \mathrm{~b}$, pode-se constatar uma boa repetitividade para as diferentes injeções, para cada um dos padrões, amostras e provas em branco.

Cabe informar que esse mesmo estudo foi realizado para $\mathrm{VT}_{\mathrm{Na}}$, $\mathrm{VT}_{\mathrm{Ca}}, \mathrm{MT}_{\mathrm{Na}}$ e $\mathrm{MT}_{\mathrm{Ca}}$ com os demais herbicidas, sendo que todos os experimentos foram conduzidos com concentração de sólidos de $1,0 \mathrm{~g}$ $\mathrm{L}^{-1}$ e de herbicidas inicialmente de $2,50 \mathrm{mg} \mathrm{L}^{-1}$, sendo sempre realizados em triplicata, além das injeções também serem efetuadas em triplicata. Na Figura 3a pode-se verificar que o sinal de ametrina é desprezível, sendo similar ao sinal da prova em branco. Todavia, para $\mathrm{VT}_{\mathrm{K}}$ (Figura 3b) o sinal obtido é semelhante àquele obtido para a solução padrão do herbicida em concentração inicial de $2,50 \mathrm{mg} \mathrm{L}^{-1}$. Fica assim constatada uma remoção altamente significativa desse herbicida da classe das triazinas por $\mathrm{MT}_{\mathrm{K}}$ e negligenciável por $\mathrm{VT}_{\mathrm{K}}$, sendo os resultados dos percentuais de remoção mostrados na Tabela 3 .

Esse ótimo desempenho da MT frente à VT na remoção do herbicida ametrina, aparentemente não evidenciou diferenciação significativa em função dos diferentes cátions interlamelares, sendo obtidos para o estudo com a MT valores médios entre 93,6 e 101,0\% de sorção, embora caiba salientar que com base no valor de LQ obtido $(0,20 \mathrm{mg}$ $\left.\mathrm{L}^{-1}\right)$ poderia se afirmar que os percentuais de remoção se situaram acima de $92 \%$. O valor de recuperação de 101,0\% sugere a ocorrência de erro analítico positivo, sendo, contudo, pouco significativo, além de apresentar baixa estimativa de desvio padrão. Caso o processo de interação fosse por troca catiônica, a $\mathrm{MT}_{\mathrm{Ca}}$ provavelmente exibiria um percentual de remoção inferior, pois do ponto de vista eletrostático, os cátions bivalentes mostrariam uma interação mais intensa e, con-
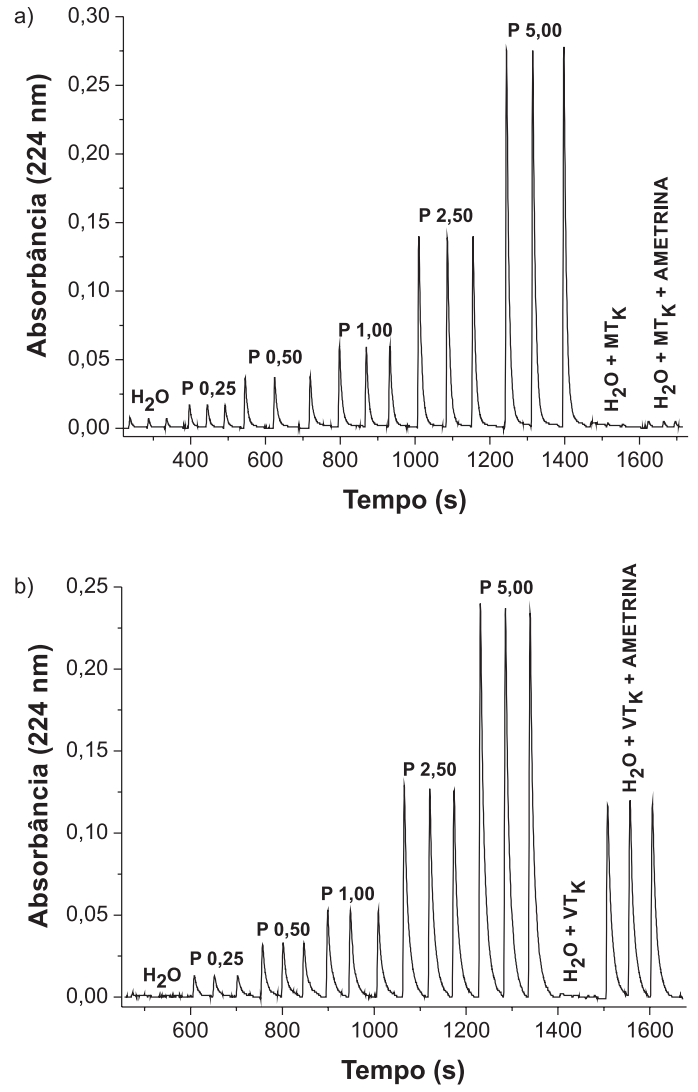

Figura 3. Registros dos sinais de absorbância obtidos para as curvas analíticas do herbicida ametrina com concentrações dos padrões entre 0,25 e 5,00 $m g L^{-1}$. A letra $P$ representa cada um dos padrões que foram analisados, nas cinco diferentes concentrações, sendo mostradas três injeções de cada padrão e três injeções de água ultrapura $\left(\mathrm{H}_{2} \mathrm{O}\right)$. 3a. Estudo da sorção de ametrina em concentração inicial de 2,50 $\mathrm{mg} \mathrm{L}^{-1}$ por $M T_{K}$ em concentração de $1,0 \mathrm{~g} \mathrm{~L}^{-1}\left(\mathrm{H}_{2} \mathrm{O}\right.$ $+M T_{K}+$ ametrina); prova em branco $\left(\mathrm{H}_{2} \mathrm{O}+M T_{K}\right) ; 3$ b. Estudo da sorção de ametrina em concentração inicial de $2,50 \mathrm{mg} \mathrm{L}^{-1}$ por $V T_{K}$ em concentração de $1,0 \mathrm{gL}^{-1}\left(\mathrm{H}_{2} \mathrm{O}+\mathrm{VT}_{\mathrm{K}}+\right.$ ametrina $)$; prova em branco $\left(\mathrm{H}_{2} \mathrm{O}+\mathrm{VT}_{K}\right)$

Tabela 3. Percentuais de remoção de ametrina para o estudo com montmorilonita e vermiculita

\begin{tabular}{cc}
\hline Argilomineral & \% sorvida (Ametrina) \\
\hline $\mathrm{MT}_{\mathrm{Na}}$ & $93,6 \pm 0,1$ \\
$\mathrm{MT}_{\mathrm{K}}$ & $101,0 \pm 0,1$ \\
$\mathrm{MT}_{\mathrm{Ca}}$ & $96,0 \pm 0,1$ \\
$\mathrm{VT}_{\mathrm{Na}}{ }^{a}$ & - \\
$\mathrm{VT}_{\mathrm{K}}$ & $4 \pm 1$ \\
$\mathrm{VT}_{\mathrm{Ca}}$ & $6 \pm 2$ \\
\hline
\end{tabular}

${ }^{\text {a }}$ não foi possível calcular.

sequentemente, o $\mathrm{Ca}^{2+}$ seria mais difícil de ser trocado. Entretanto, esse íon é mais facilmente hidratável, portanto, seria mais fácil de ser deslocado da camada interlamelar, visto que as moléculas de água de hidratação estariam ligadas ao argilomineral, ao contrário do $\mathrm{K}^{+} \mathrm{e} \mathrm{Na}^{+}$, os quais estariam ligados diretamente ao argilomineral e, portanto, mais difíceis de serem trocados. ${ }^{35,38}$ Dessa forma, supõe-se que os íons de cálcio hidratados seriam deslocados mais facilmente e o percentual de remoção seria superior para $\mathrm{MT}_{\mathrm{Ca}}$, o que não ocorreu, sugerindo que o processo de interação não seja por troca interlamelar. Além disso, o pH do meio, entre 6,0 e 7,0, não seria favorável para protonação do herbicida, o que indica que o mesmo seja sorvido como uma molécula 
neutra por interações de van der Waals e ligações de hidrogênio.

Como a $\mathrm{MT}_{\mathrm{K}}$ evidenciou os melhores resultados, esse argilomineral foi selecionado para o estudo de sorção com atrazina e simazina, além de ter sido realizado novamente o experimento para a ametrina. Os percentuais de sorção de $87 \pm 2 ; 56 \pm 4$ e $69 \pm 10$ foram obtidos para ametrina, atrazina e simazina, respectivamente. Apesar de bem inferiores aos valores observados para a ametrina, os percentuais de remoção foram bastante significativos. Percentuais de sorção elevados para $\mathrm{MT}_{\mathrm{K}}$ (próximo de 99\%) já haviam sido relatados na literatura, ${ }^{16}$ para o herbicida atrazina e alguns de seus metabólitos, bem como percentuais desprezíveis para remoção desses compostos de meio aquoso por $\mathrm{VT}_{\mathrm{K}}$. Esse desempenho superior da MT frente à VT como fase sorvente para a ametrina, possivelmente esteja relacionado com a maior área superficial da mesma (Tabela 2), visto que em termos de $\mathrm{pH}$, ambos argilominerais apresentaram valores semelhantes $(6,0 \mathrm{a} 7,0)$.

$\mathrm{Na}$ literatura é mostrado que além da atrazina, o herbicida propazina e os metabólitos da atrazina exibem ótimos percentuais de remoção, superiores a $90 \%$ na maioria dos casos, ${ }^{32}$ sendo comparáveis a fases comerciais C-18 o que, aliado a este estudo, sugere que a montmorilonita consiste de um excelente material para atuar como fase de concentração analítica para herbicidas e metabólitos da classe das triazinas. Essa particularidade parece estar relacionada com o fato de bases fracas, como triazinas, poderem ter grupos $\mathrm{NH}$ protonados e dessa forma poderem ser sorvidos em decorrência da distribuição de cargas negativas dos argilominerais. ${ }^{38}$ Como mencionado anteriormente, isso não ocorreria nas condições de $\mathrm{pH}$ dos experimentos; entretanto, a literatura reporta que o $\mathrm{pH}$ da superfície dos argilominerais é muito inferior àquele evidenciado no seio da solução (6,0 a 7,0 neste estudo), o que poderia provocar o processo de protonação de bases fracas como as triazinas. ${ }^{35}$ Isso é reforçado por processos de tratamento interlamelares, nos quais há a intercalação de espécies como $\mathrm{Fe}^{3+}$, que geram uma redução no valor de $\mathrm{pH}$ em argilominerais, ou mesmo pela simples redução do $\mathrm{pH}$ do meio, sendo que em ambos os casos há um aumento no processo de sorção da VT. ${ }^{16}$

Para os demais herbicidas estudados, 2,4-D; diuron, alacloro e metolacloro, não foram observados processos de interação com os argilominerais, com exceção da $\mathrm{MT}_{\mathrm{K}}$ com o diuron, a qual apresentou um processo de remoção de aproximadamente $20 \%$ desse herbicida. Não foram observadas reduções dos sinais de absorbância nos registros por FIA-UV, sugerindo não haver processo de interação entre VT ou MT com esses herbicidas. Não foi verificado, também, qualquer tipo de diferenciação para MT ou VT, pelo menos nas condições estudadas de $1,0 \mathrm{~g} \mathrm{~L}^{-1}$ dos argilominerais, $2,50 \mathrm{mg} \mathrm{L}^{-1}$ como concentração inicial de cada um dos herbicidas e tempo de contato de $30 \mathrm{~min}$. Deve-se ressaltar que tempos maiores que $30 \mathrm{~min}$ não foram investigados, em função da intenção de emprego das fases sorventes como concentradores analíticos, o que sob o ponto de vista de frequência analítica seria indesejável. Esses herbicidas parecem apresentar processos de sorção pouco significativos em argilominerais e por isso processos de sorção em meio aquoso com aplicações ambientais para argilominerais, vêm sendo estudados, porém após modificação interlamelar, ${ }^{39,40}$ e não nas formas naturais como foi o propósito deste estudo.

Embora o desempenho dos argilominerais tenha sido totalmente desfavorável para os mesmos serem empregados como sorventes para esses herbicidas, do ponto de vista ambiental ou analítico, deve-se ressaltar que a MT apresentou um aspecto atrativo, no que diz respeito à seletividade às triazinas, frente aos demais herbicidas - 2,4-D; diuron, alacloro e metolacloro.

\section{Estudo da variação de pH}

Como os resultados obtidos com o procedimento anterior se mostraram pouco satisfatórios, com exceção para os compostos tria- zínicos, foi realizado um novo estudo, visando avaliar a influência do $\mathrm{pH}$ na sorção dos herbicidas. Inicialmente, foi investigado o tempo de contato ideal para proporcionar um equilíbrio aparente entre o argilomineral e $\mathrm{H}_{3} \mathrm{O}^{+}$do meio, sendo constatado ser necessário um tempo de $3 \mathrm{~h}$ para se obter tal condição. Os valores aproximados de $\mathrm{pH}$ de 2,6; 2,0 e 1,0 foram obtidos para as adições de $\mathrm{HCl}$ nas concentrações de 2,5; 10 e $100 \mathrm{mmol} \mathrm{L}^{-1}$, respectivamente, após $3 \mathrm{~h}$ de tempo de contato. Após determinar esse tempo ideal, os estudos de sorção com variação de $\mathrm{pH}$ foram realizados com os sorventes preparados de VT para o herbicida ametrina, e com MT e VT para o herbicida diuron. Não se utilizou a MT para o herbicida ametrina, devido a esse herbicida ter apresentado bons resultados de sorção com esse argilomineral.

Os dois estudos (ametrina e diuron) foram realizados em concentração inicial de $2,50 \mathrm{mg} \mathrm{L}^{-1} \mathrm{e}$ em concentração de argilominerais de $1,0 \mathrm{~g} \mathrm{~L}^{-1}$, tendo sido mantidos idênticos todos os detalhes inerentes ao método analítico. Em todos os sinais obtidos por FIA-UV, foram constatadas dificuldades na quantificação do herbicida, uma vez que as provas em branco exibiram sinais relativamente elevados, especialmente para os casos com concentração de ácido mais elevada, sendo que, em alguns casos, os sinais das provas em branco eram similares aos padrões e ainda com o problema adicional de não apresentarem boa repetitividade. Cabe salientar que, em função dessa limitação, foi verificado se havia interferência das injeções do ácido no comprimento de onda sob estudo (224 nm), a qual não foi observada. Isso foi indicativo de que os processos de centrifugação e filtração não foram eficazes para resolver essas dificuldades, como fora anteriormente. Ainda assim, nos casos em que o $\mathrm{pH}$ foi de 2,0 e 2,6, para $\mathrm{VT}_{\mathrm{Na}}, \mathrm{VT}_{\mathrm{K}}$ e $\mathrm{VT}_{\mathrm{Ca}}$, foi possível estimar as concentrações de ametrina remanescentes, obtendo-se percentuais de remoção de aproximadamente 48 e $28 \%$, da concentração inicial de $2,50 \mathrm{mg}$ $\mathrm{L}^{-1}$ da ametrina, para $\mathrm{pH}$ 2,0 e 2,6, respectivamente. Embora esses valores não sejam muito significativos, demonstram um processo de sorção mais relevante frente ao estudo da ametrina sem ajuste de $\mathrm{pH}$, para o qual praticamente nenhum processo de sorção havia sido constatado. Resultados semelhantes para aumento nos percentuais de sorção de compostos triazínicos com a diminuição do valor de $\mathrm{pH}$, em sistemas contendo argilominerais, já haviam sido descritos na literatura, ${ }^{35}$ em decorrência da protonação dos grupos $\mathrm{NH},{ }^{38} \mathrm{o}$ que, contudo, sob o ponto de vista ambiental ou analítico, foi pouco significativo no presente estudo.

Para os estudos com o herbicida diuron com VT e MT, foi mais difícil avaliar o processo de sorção, pelo mesmo problema observado para o estudo com a ametrina, embora o comprimento de onda utilizado $(248 \mathrm{~nm})$ a princípio fosse mais favorável, pois poderia estar mais livre de interferências. Ainda assim, foi possível verificar que, ao contrário da ametrina, nenhuma modificação no processo de sorção foi observada para os valores de $\mathrm{pH}$ estudados. Devido a esses resultados insatisfatórios com as provas em branco, decidiu-se dar continuidade ao estudo de sorção e dessorção com o estudo para MT, pelo fato deste argilomineral ter demonstrado resultados mais promissores em nível analítico e ambiental.

\section{Estudo de recuperação do herbicida ametrina com montmorilonita}

Este estudo foi realizado empregando $\mathrm{MT}_{\mathrm{K}}$ com o herbicida ametrina. Nesse procedimento não se realizou ajuste de $\mathrm{pH}$, sendo obtido pH final próximo de 6,0, após o tempo de contato de $30 \mathrm{~min}$ entre a $\mathrm{MT}_{\mathrm{K}}$ com a solução de ametrina, em concentração inicial de $0,10 \mathrm{mg} \mathrm{L}^{-1}$ do herbicida. Novas curvas analíticas foram realizadas para esse herbicida, sendo que para os extratos obtidos seriam esperadas concentrações em torno de 1,0 $\mathrm{mg} \mathrm{L}^{-1}$. Todavia, após completa 
remoção da acetona, solubilização dos extratos em meio aquoso e filtração em membrana, foram obtidos resultados muito superiores a $100 \%$ de recuperação, além de repetitividade muito ruim, com resultados variando entre 139 e próximo de $200 \%$ de recuperação.

Os altos resultados encontrados parecem ser devidos aos sinais gerados pelo argilomineral, após centrifugação mesmo com a filtração em membrana. Seria importante trocar o sistema de quantificação, visando uma melhor avaliação do método proposto, utilizando cromatografia em fase líquida, conforme a literatura. ${ }^{32}$

\section{CONCLUSÕES}

O método de quantificação empregando FIA-UV foi afetado por limitações relacionadas às soluções das provas em branco, gerando elevados sinais de absorbância, provavelmente em decorrência da presença de partículas coloidais originárias do argilomineral. Essas dificuldades puderam ser minimizadas pelo emprego de filtração em membrana com abertura de poro de $0,45 \mu \mathrm{m}$.

Os herbicidas 2,4-D, diuron, alacloro e metolacloro não exibiram interação com MT ou VT, ao passo que ametrina, atrazina e simazina mostraram bons percentuais de remoção com MT; não sendo, contudo, constatada interação com a VT, que apresentou um ganho no processo de sorção com a diminuição do $\mathrm{pH}$. Não houve diferenças pronunciadas entre $\mathrm{MT}_{\mathrm{K}}, \mathrm{MT}_{\mathrm{Na}}$ e $\mathrm{MT}_{\mathrm{Ca}}$, sugerindo não haver processo de sorção por troca interlamelar. Os resultados obtidos de sorção sugerem ser possível utilizar o argilomineral MT para remoção de herbicidas da classe das triazinas de meio aquoso, bem como utilizar como fase de concentração analítica, aliado ao fato de ter apresentado uma boa seletividade com relação a herbicidas de outras classes. Todavia, seria adequada a utilização de uma técnica analítica de separação como cromatografia em fase líquida, para a quantificação dos herbicidas e realização de experimentos adicionais de recuperação, em decorrência das interferências que foram observadas.

\section{AGRADECIMENTOS}

Ao apoio financeiro concedido pela CAPES (Processo PROCAD 0082/05-8) e pelas bolsas de estudo concedidas.

\section{REFERÊNCIAS}

1. http://www.sindag.com.br/, acessada em Agosto 2009.

2. Abhilash, P. C.; Singh, N.; J. Hazard. Mater. 2009, 165, 1.

3. Ferracini, V. L.; Queiroz, S. C. N.; Gomes, M. A. F.; Santos, G. L.; Quim. Nova 2005, 28, 380.

4. Armas, E. D.; Monteiro, R. T. R.; Antunes, P. M.; dos Santos, M. A. P. F.; de Camargo, P. B.; Abakerli, R. B.; Quim. Nova 2007, 30, 1119.

5. Riemens, M. M.; Dueck, T.; Kempenaar, C.; Lambertus, A. P. L.; Martin, J. J.; Environ. Pollut. 2009, 157, 2306.

6. Primel, E. G.; Zanella, R.; Kurz, M. H. S.; Goncalves, F. F.; Machado, S. O.; Marchezan, E.; Quim. Nova 2005, 28, 605.

7. http://www.mma.gov.br/port/conama/res/res05/res35705.pdf, acessada em Julho 2009.

8. http://www.anvisa.gov.br/, acessada em Julho 2009.

9. Inoue, M. H.; Oliveira Jr., R. S.; Regitano, J. B.; Tormena, C. A.; Tornisielo, V. L.; Constantin, J.; Planta Daninha 2003, 21, 313.
10. Fava, L.; Orrù, M. A.; Scardala, S.; Funari, E.; Microchem. J. 2007, 86, 204.

11. El Imache, A.; Dahchour, A; Elamrani, B.; Dousset, S.; Pozzonni, F.; Guzzella, L.; J. Environ. Sci. Health, Part B 2009, 44, 31.

12. Jablonowski, N. D.; Koeppchen, S.; Hofmann, D.; Schaeffer, A.; Burael, P.; J. Agric. Food Chem. 2008, 56, 9548.

13. Dictor, M-C.; Baran, N.; Gautier, A.; Mouvet, C.; Chemosphere 2008, 71,663 .

14. Celano, G.; Šmejkalová; Spaccini, R.; Piccolo, A.; J. Agric. Food Chem. 2008, 56, 7360 .

15. Pateiro-Moure, M.; Pérez-Novo, C.; Arias-Estévez, M.; Rial-Otero, R.; Simal-Gándara, J.; J. Colloid Interface Sci. 2009, 333, 431.

16. Abate, G.; Masini, J. C.; J. Agric. Food Chem. 2005, 53, 1612.

17. Froehner, S.; Martins, R. F.; Furukawa, W.; Errera, M. R.; Water, Air, Soil, Pollut. 2009, 199, 107.

18. Dordio, A. V.; Candeias; A. J. E.; Pinto, A. P.; Costa, C. T.; Carvalho, A. J. P.; Ecological Engineering 2009, 35, 290.

19. Gitipour, S.; Bowers, M. T.; Bodocsi, A.; J. Colloid Interface Sci. 1997, 196, 191.

20. Teixeira-Neto, E.; Teixeira-Neto, A. A.; Quim. Nova 2009, 32, 809.

21. Lagaly, G.; Appl. Clay Sci. 2001, 18, 205.

22. Reinoso, F. R.; Adsorbentes en la solución de algunos problemas ambientales, Ed. Cyted: Madri, 2004.

23. Cornejo, L.; Celis, R.; Domínguez, C.; Hermosín, M. C.; Cornejo, J.; Appl. Clay Sci. 2008, 42, 284.

24. Aktaş, Y. K.; Fresenius Environ. Bull. 2005, 14, 993.

25. Dias Filho, N. L.; Carmo, D. R.; Talanta 2006, 68, 919.

26. Rajesh, N.; Mishra, B. G.; Pareek, P.; Spectrochim. Acta, Part A 2008, 69,612 .

27. Afzali, D.; Mostafavi, A.; J. AOAC Int. 2008, 91, 1430.

28. Lanças, F. M.; Extração em fase sólida (SPE), Rima Ed: São Carlos, 2004.

29. Queiroz, S. C. N.; Melo, L. F. C.; Jardim, I. C. S. F.; Quim. Nova 2006, 29, 637.

30. van Pinxteren, M.; Bauer, C.; Popp, P.; J. Chromatogr., A 2009, 1216, 5800 .

31. Bucheli, T. D.; Muller, S. R.; Reichmuth, P.; Haderlein, S. B.; Schwarzenbach, R.; Anal. Chem. 1999, 71, 2171.

32. Zarpon, L.; Abate, G.; dos Santos, L. B. O.; Masini, J. C.; Anal. Chim. Acta 2006, 579, 81.

33. Rodrigues, B. N.; Almeida, F. S.; Guia de herbicida, Grafmarke Ed.: Londrina, $5^{\mathrm{a}}$ ed., 2005.

34. Cabrera, L.; Costa, F. P.; Primel, E. G.; Quim. Nova 2008, 31, 1982.

35. McBride, M. B.; Environmental Chemistry of soils, Oxford University Press: New York, 1994.

36. Pinto, A. C.; de Oliveira, C. H.; Ribeiro, N. M.; Quim. Nova 2008, 31, 562.

37. Marcos, C.; Arango, Y. C.; Rodriguez, I.; Appl. Clay Sci. 2009, 42, 368.

38. Sposito, G.; The Chemistry of Soils, Oxford University Press: New York, 1989.

39. Bouras, O.; Bollinger, J-C.; Baudu, M.; Khalaf, H.; Appl. Clay Sci. 2007, $37,240$.

40. Cornejo, L.; Celis, R.; Domínguez, C.; Hermosín, M. C.; Cornejo, J.; Appl. Clay Sci. 2008, 42, 284. 